\title{
Kabuki Syndrome and Anorectal Malformations: Implications for Diagnosis and Treatment
}

\author{
Sotirios Siminas ${ }^{1}$ Colin Tennant Baillie ${ }^{2}$ Richard Turnock ${ }^{2}$ \\ ${ }^{1}$ Department of Paediatric Surgery and Urology, Manchester \\ Children's Hospital, Manchester, United Kingdom \\ 2 Paediatric Surgery Department, Alder Hey Children's Hospital, \\ Liverpool, United Kingdom \\ Address for correspondence Sotirios Siminas, MD, PhD, FEBPS, \\ Department of Paediatric Surgery and Urology, Manchester Children's \\ Hospital, Oxford Road, Manchester M13 9WL, United Kingdom \\ (e-mail: siminas1@gmail.com).
}

Eur J Pediatr Surg Rep 2015;3:54-58.

\begin{abstract}
Kabuki syndrome (KS) is a rare genetic condition characterized by a distinctive facies, intellectual disability, growth delay, and a variety of skeletal, visceral, and other anomalies, including anorectal malformations (ARMs). We present two cases of female patients with KS, diagnosed and successfully managed at our institution, one with a perineal fistula and one with a rectovestibular fistula. Our report, along with a literature review, shows that the syndrome is usually associated with "low" anomalies, with a potential for a good prognosis. Management of the anorectal anomaly in patients with $\mathrm{KS}$ is not essentially different from that in other nonsyndromic patients, taking into account the frequent association of the syndrome with serious congenital heart disease, which might affect the decision-making and timing of the stages of anorectal

Keywords

- Kabuki syndrome

- anorectal malformations

- chromosomal abnormalities reconstruction. The frequent occurrence of learning and feeding difficulties makes establishment of toilet training and bowel management rather more challenging, requiring the expertise of a multidisciplinary team. The finding of ARMs in female patients with other characteristics of KS, although inconstant, could support the clinical suspicion for the syndrome until genetic confirmation is available, and should alert the physician for the potential of severe cardiac defects.
\end{abstract}

\section{Introduction}

Kabuki syndrome (KS) is a rare genetic condition characterized by clinical variability and genetic heterogeneity, whose molecular basis was only recently identified. ${ }^{1}$ Niikawa and Kuroki in 1981 first described the constellation of a distinctive facies, intellectual disability, growth delay, and a variety of skeletal, visceral, and other malformations. ${ }^{2}$ The syndrome derives its name from the resemblance of the patient's facies to the makeup of the actors of the Japanese dance-drama theater Kabuki. Although literature review as well as our own experience, shows that the syndrome is most frequently related with anorectal anomalies of favorable prognosis, the association with major congenital heart defects and other anomalies, makes short- and long-term management challenging. We

received

November 10, 2014

accepted after revision

February 2, 2015

published online

May 28, 2015 present two cases of patients with KS treated in our institution with emphasis on the anorectal aspects of the syndrome.

\section{Case 1}

The patient was referred to us at the 22nd day of life and was noted to have a perineal fistula and groove and an anal index of less than 0.35 . She was born prematurely at 32 weeks of gestation and was also diagnosed with pulmonary artery stenosis and multiple other congenital anomalies (-Table 1 ). KS was clinically suspected initially by the characteristic facies and the constellation of other anomalies and eventually confirmed, when the tests became available by demonstrating the introduction of a premature stop mutation in the MLL2 gene (MLL2/KMT2D MIM\# 602113). Her stenotic anus
License terms Stuttgart · New York

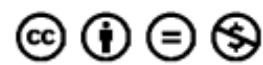


Table 1 Constellation of anomalies in the reported patients

\begin{tabular}{|c|c|c|}
\hline & Patient 1 & Patient 2 \\
\hline Face & $\begin{array}{l}\text { Kabuki facies (ear malformations, epicanthus) } \\
\text { Diversion squint in right eye }\end{array}$ & Facies, natal teeth \\
\hline Musculoskeletal & $\begin{array}{l}\text { Congenital hip dysplasia: Surgery } \\
\text { Bilateral polydactyly of feet }\end{array}$ & Congenital hip dysplasia \\
\hline Cranium & Trigonocephaly: Surgery & Plagiocephaly \\
\hline Cognitive & Mild learning difficulties & Learning difficulties \\
\hline Anorectal & Anterior anus and perineal groove & $\begin{array}{l}\text { Anovestibular fistula decompressing through fistula } \\
\text { though-dilatations-washouts }\end{array}$ \\
\hline Surgery & $\begin{array}{l}\text { Sphincter mapping-dilatations-table- } \\
\text { contrast enema: No megarectum }\end{array}$ & PSARP + colostomy and colostomy closure (8 wks) \\
\hline Urogenital & & Bilateral duplex kidney-vesicoureteral reflux \\
\hline Cardiac & $\begin{array}{l}\text { Pulmonary stenosis and patent ductus arteriosus } \\
\text { Surgery at the age of } 1 \mathrm{y}\end{array}$ & Fallot tetralogy-double outlet right ventricle-surgery \\
\hline Other GI & & $\begin{array}{l}\text { Feeding difficulties } \\
\text { Gastroesophageal reflux }\end{array}$ \\
\hline Spinal & & US: Normal \\
\hline Others & Prematurity 32/40 w & $\begin{array}{l}\text { Twin, premature, } 35 / 40 \text { w } \\
\text { Hypotonia }\end{array}$ \\
\hline Management & $\begin{array}{l}\text { Dilatations } \\
\text { Laxatives }\end{array}$ & $\begin{array}{l}\text { Preoperative and postoperative dilatations } \\
\text { Laxatives }\end{array}$ \\
\hline
\end{tabular}

was initially treated with dilatations (starting from a Hegar no. 9) that allowed for bowel decompression and was started on stool softeners (lactulose) from the 1 st month of life, while being followed regularly in the anorectal clinic. Spinal ultrasound early in neonatal life revealed no structural abnormalities of the caudal spine. After dilatations reached a caliber of a Hegar no. 12 at the age of 1 year, they were discontinued. At the age of 1.5 years and after undergoing cardiac surgery, we performed anal sphincter mapping under anesthetic which showed that although the position of the fistula-anus, based on the anal index was rather anterior, approximately three quadrants of the fistula were passing through the external sphincter. An on-table contrast enema showed absence of megarectum, and a decision was made to manage the anorectal anomaly conservatively, given the lack of retentive symptoms. She has been regularly followed up, and at the last clinic visit (4-years-old) she was doing very well, being entirely toilet trained and requiring regular use of small doses of oral and rectal laxatives.

\section{Case 2}

The patient was first seen by us at the age of 4 months due to an imperforate anus with a rectovestibular fistula. She was born as one of the twins at 35 weeks of gestation and was soon diagnosed with a large atrioventricular septal defect and patent ductus arteriosus which caused intractable heart failure for which she eventually required cardiac surgery. She was also found to have other multiple congenital anomalies (-Table 1). Spinal ultrasound early in neonatal life revealed no structural abnormalities of the caudal spine. As per the institutional practice from the referring center, she was initially managed with rectal washouts through the fistula, in view of a primary definite repair after stabilization of the cardiac condition. Following the cardiac surgery, she underwent a posterior sagittal anorectoplasty with covering sigmoidostomy at the age of 9 months. Following the genetic review, the constellation of her anomalies was attributed to $\mathrm{KS}$, mainly based on the characteristic facies associated with the syndrome and was later confirmed after genetic testing demonstrating anomalies in the MLL2 gene. After dilating her anus to a Hegar no. 13, the colostomy was closed and the patient was followed up in the anorectal clinic for bowel management. At the time of the last follow-up (3.5 years of age), she had a good functional result with frequent bowel motions and occasional only use of laxatives, having started toilet training.

\section{Discussion}

The two cases highlighted here, as well as a literature review $^{2-7}$ (-Table 2) show that when KS is associated with anorectal malformations (ARMs), the affected patients are females and the ARM type is either a rectovestibular or a rectoperineal fistula, both considered to have a good functional prognosis. As some of the reviewed articles were published before the Krickenbeck consensus, the terms used to describe the anomalies vary, and some of the older cases were described as anterior stenotic anus.

$\mathrm{KS}$ is a rare disease, with estimates of prevalence ranging from 1 to 32,000 for Japanese children and 1 to 86,000 for Australian and New Zealand children. ${ }^{1}$ In 2010, mutations in 
Table 2 Reported cases with Kabuki syndrome in the literature

\begin{tabular}{|c|c|c|c|c|}
\hline S. no. & Author (Y) & Type of ARM & Surgery & Other anomalies \\
\hline 1 & Matsumura et al $(1992)^{3}$ & Vestibular fistula & Anal transposition ${ }^{a}$ & $\begin{array}{l}\text { Cleft palate, ASD, webbed neck, renal } \\
\text { anomalies, long great toes }\end{array}$ \\
\hline 2 & Matsumura et al $(1992)^{3}$ & Vestibular fistula & Anal transposition ${ }^{a}$ & $\begin{array}{l}\text { Cleft palate, VSD, aortic aneurysm, } \\
\text { horse-shoe kidney, bifid renal pelvis, } \\
\text { pigmented retina, abnormal EEG }\end{array}$ \\
\hline 3 & Matsumura et al $(1992)^{3}$ & Vestibular fistula & “Cut-back” procedure ${ }^{\mathrm{b}}$ & Autism, retardation in bone age \\
\hline 4 & Matsumura et al $(1992)^{3}$ & Vestibular fistula & Anal transposition ${ }^{\mathrm{b}}$ & $\begin{array}{l}\text { Renal agenesis, hip dysplasia, retarda- } \\
\text { tion in bone age, VSD }\end{array}$ \\
\hline 5 & Philip et al (1992) ${ }^{4}$ & Vestibular fistula & PSARP & $\mathrm{N} / \mathrm{A}$ \\
\hline 6 & Kokitsu-Nakata et al (1999) & Vestibular fistula & Bowel management & $\begin{array}{l}\text { Facies, growth retardation, cleft palate, } \\
\text { ectopic right kidney, finger anomalies }\end{array}$ \\
\hline 7 & Kawame et al (1999) $^{6}$ & Perineal fistula & PSARP & N/A \\
\hline 8 & Abdel-Salam et al $(2008)^{7}$ & Vestibular fistula & PSARP & $\begin{array}{l}\text { Diaphragmatic defect, congenital } \\
\text { heart defects, cleft palate, lower lip } \\
\text { pits, hypopigmentation, seizures, } \\
\text { hyperlaxity of joints and premature } \\
\text { breast development }\end{array}$ \\
\hline 9 & Present study & Perineal fistula & Bowel management & $\begin{array}{l}\text { Facies, hip dysplasia, trigonocephaly, } \\
\text { finger anomalies, pulmonary artery } \\
\text { stenosis, learning difficulties }\end{array}$ \\
\hline 10 & Present study & Vestibular fistula & PSARP & $\begin{array}{l}\text { Facies, hip dysplasia, plagiocephaly, } \\
\text { Fallot tetralogy, duplex kidneys, hypo- } \\
\text { tonia, learning difficulties }\end{array}$ \\
\hline
\end{tabular}

Abbreviation: PSARP, posterior sagittal anorectoplasty.

Note: All patients studied are females.

${ }^{\text {a }}$ Procedure listed as described by reporting authors, although terms do not reflect current nomenclature. Most likely term: anterior sagittal approach.

${ }^{b}$ Procedure listed as described by reporting authors, although terms do not reflect current nomenclature. Most likely term: perineal operation-anoplasty.

the gene KMT2D (MLL2) were identified as the major genetic cause for the disease in 56 to $75 \%$ of the patients affected. ${ }^{8}$ Other mutations have also been identified in the gene KDM6A (UTX), ${ }^{9}$ but almost $30 \%$ of the patients with the syndrome have no recognizable genetic anomaly identified. ${ }^{1}$ The mainstay of diagnosis is the typical facial gestalt with long palpebral fissures, eversion of the lower eyelid, arched eyebrows, short columella, thin upper lip, slanted downward mouth corners, and sometimes prognathism. Other maxillofacial anomalies include cleft lip and palate (12-50\%), dentition anomalies (53-100\%), and craniosynostosis. Failure to thrive due to feeding difficulties has been documented in 65 to $74 \%$ of the patients, with short stature in approximately $58 \%$. Learning difficulties are rather the rule than the exception, with more than $90 \%$ of the patients having some form of impairment. Other anomalies include a variety of skeletal malformations (more than $80 \%$, vertebral anomalies or scoliosis, brachydactyly, or clinodactyly), ocular anomalies (38$61 \%$ ), endocrine disorders (early breast development the most common), cardiac defects (40-50\%, most common atrial septal defect- ventricular septal defect), urogenital anomalies in 30 to $40 \%$ (hydronephrosis and ectopia), hearing loss, and susceptibility to middle ear infections. Characteristic features are also the presence of persistent fetal finger pads (up to 92\%) and abnormalities of the dermatoglyphic pattern. The syndrome has also been associated with a variety of autoimmune disorders and malignancy (medulloblastoma, non-Hodgkin lymphoma), and a susceptibility to respiratory infections is well documented. ${ }^{1,2,6}$ The association with ARMs is estimated to be around $7 \% .^{3}$ The management of the anorectal anomaly in patients with $\mathrm{KS}$ is not essentially different from that in other nonsyndromic patients, but one must take into account the frequent association of the syndrome with serious congenital heart disease, which might affect the decision-making and timing of the stages in anorectal reconstruction. A major cardiac defect might warrant surgical treatment before definite anorectal reconstruction, and in these instances, dilatations of the perineal fistula or a decompressing colostomy might prove useful. The frequent occurrence of learning and feeding difficulties make the establishment of toilet training and bowel management rather more challenging. The importance of a multidisciplinary team in the management of these complex patients cannot be overemphasized. The fact though that these anomalies are usually in the mild end of the ARM spectrum offer a good anorectal functional prognosis, as was the case for our two patients.

The association of specific syndromes with specific types of ARMs is well documented, as in the case of trisomy 21 linked with anomalies without fistula, ${ }^{10}$ or Currarino syndrome presenting with a perineal fistula or funnel anus, ${ }^{10,11}$ while other syndromes or chromosomal anomalies do not 
follow a set pattern. Due to the rarity of the disease and the rather infrequent association with ARMs, it is uncertain whether KS follows such a pattern, although all reported cases represent ARM at the mild end of the spectrum, which could be associated with good prognosis, provided there are no other risk factors of a poor outcome (dysraphic anomalies, severe developmental delay). The etiopathogenesis of this association, and of the occurrence in females in the reported cases, is yet unclear due to the limited knowledge regarding the gene transcription regulated by the KMT2D complex during embryogenesis.

In conclusion, our data, along with data from the literature, show that the finding of ARMs in female patients with other characteristics of KS, although inconstant, could support the clinical suspicion for the syndrome until genetic confirmation is available, although pediatric surgeons should be aware of the high probability of serious cardiac defects.

Conflict of Interest

None.

\section{References}

1 Bögershausen N, Wollnik B. Unmasking Kabuki syndrome. Clin Genet 2013;83(3):201-211
2 Niikawa N, Kuroki Y, Kajii T, et al. Kabuki make-up (NiikawaKuroki) syndrome: a study of 62 patients. Am J Med Genet 1988; 31(3):565-589

3 Matsumura M, Yamada R, Kitani Y, et al. Anorectal anomalies associated with Kabuki make-up syndrome. J Pediatr Surg 1992; 27(12):1600-1602

4 Philip N, Meinecke P, David A, et al. Kabuki make-up (NiikawaKuroki) syndrome: a study of 16 non-Japanese cases. Clin Dysmorphol 1992;1(2):63-77

5 Kokitsu-Nakata NM, Vendramini S, Guion-Almeida ML. Lower lip pits and anorectal anomalies in Kabuki syndrome. Am J Genet 1993;47:423-425

6 Kawame H, Hannibal MC, Hudgins L, Pagon RA. Phenotypic spectrum and management issues in Kabuki syndrome. J Pediatr 1999;134(4):480-485

7 Abdel-Salam GM, Afifi HH, Eid MM, el-Badry TH, Kholoussi NM. Anorectal anomalies, diaphragmatic defect, cleft palate, lower lip pits, hypopigmentation and hypogammaglobulinemia A in Kabuki syndrome: a rare combination. Genet Couns 2008;19(3):309-317

$8 \mathrm{Ng} \mathrm{SB}$, Bigham AW, Buckingham KJ, et al. Exome sequencing identifies MLL2 mutations as a cause of Kabuki syndrome. Nat Genet 2010;42(9):790-793

9 Lederer D, Grisart B, Digilio MC, et al. Deletion of KDM6A, a histone demethylase interacting with MLL2, in three patients with Kabuki syndrome. Am J Hum Genet 2012;90(1):119-124

10 Martuciello G. Genetics of anorectal malformations. In: Anorectal Malformations in Children. Holschneider AM, Hutson JM, eds. Berlin, Heidelberg: Springer Verlag; 2006:17-30

11 Suomalainen A, Wester T, Koivusalo A, Rintala RJ, Pakarinen MP. Congenital funnel anus in children: associated anomalies, surgical management and outcome. Pediatr Surg Int 2007;23(12):1167-1170 